\title{
Relation of Cholesterol Level to Dietary Fat Intake in Patients of Ischemic Heart Disease
}

\author{
Hamid Mahmood ${ }^{1 *}$, Abdul Rehman Abid ${ }^{2}$, Rehan Riaz ${ }^{3}$ and Nadeem Hayat Mallick ${ }^{4}$ \\ ${ }^{1}$ Additional Medical Superintendent, Punjab Institute of Cardiology, Lahore, Pakistan \\ ${ }^{2}$ Specialist Cardiology, Department of Cardiology, Heart Hospital, Hamad Medical Corporation, Doha, Qatar \\ ${ }^{3}$ Senior registrar cardiology, Faisalabad institute of cardiology, Faisalabad, Pakistan \\ ${ }^{4}$ Professor of Cardiology, Punjab Institute of Cardiology, Lahore, Pakistan
}

\begin{abstract}
Objective: To study the association of cholesterol level and dietary habits in patients of ischemic heart disease admitted with acute coronary syndromes.

Materials and Methods: A total of 404 patients of ischemic heart disease admitted at the Punjab Institute of Cardiology, Lahore were included in the study. Patients were divided into four groups. Group I: 176(45.5\%) patients with normal cholesterol levels and low fat diet. Group II: 76(18.2\%) patients with normal cholesterol levels on high fat diet. Group III: 113(27.9\%) patients with high cholesterol levels on low fat diet. Group IV: $39(9.6 \%)$ patients with high cholesterol levels on high fat diet.

Results: Mean age of the study population was $55.6 \pm 12.3$ years. Mean age was similar in all the groups $(p<$ $0.127)$. Overall $308(76.2 \%)$ patients were males and $96(23.8 \%)$ were females. Mean caloric intake of the study patients was $2570.5 \pm 936.7$. Caloric intake was highest in Group I followed by Group III. Group II and IV had lower caloric intake than groups I and III ( $p<0.0001)$. Similarly percent fat was also lower in Group I and III as compared to Groups II and IV $(p<0.008)$. Mean cholesterol level of the study population was $154.5 \pm 42.6 \mathrm{mg} / \mathrm{dl}$. Mean cholesterol level was highest in Group III, $195.9 \pm 38.8 \mathrm{mg} / \mathrm{dl}$ (despite on low fat diet) followed by Group IV, $193.6 \pm 39.5$ (on high fat diet). Mean cholesterol was similar in Group I, $130.3 \pm 19.6$ and Group II, $129.1 \pm 20.4(p<0.0001)$ irrespective of dietary intake of fat. Low HDL in Group I and II patients even having normal cholesterol level lead to acute myocardial infarction.
\end{abstract}

Conclusion: Dietary intake of fat has no influence on cholesterol levels. Low HDL is an important risk factor leading to acute myocardial infarction and is not influenced by fat intake in diet.

\section{Keywords}

Acute myocardial infarction; Cholesterol; High density lipoprotein cholesterol; High fat diet

\section{Introduction}

Despite revolutionary achievements in diagnosis and management over the last three decades, ischemic heart disease (IHD) continues to be a major public health problem in the industrialized world $[1,2]$.

Epidemiological surveys have shown that serum total cholesterol levels are continuously correlated with ischemic heart disease risk over a broad range of cholesterol values. This relationship has been observed in many populations throughout the world [3-6]. Although the association between cholesterol levels and IHD risk is continuous, it is not linear; risk rises more steeply with increasing cholesterol concentrations. Thus, at any level of cholesterol, for a given milligramper-deciliter change in the cholesterol level, the change in relative risk is the same as at any other cholesterol level [3,4]. Heart Protection Study results suggest that reducing serum cholesterol from any baseline level further lowers risk in high-risk patients. In Heart Protection Study, absolute risk reductions for major vascular events were smaller at lower cholesterol levels because the risk imparted by higher cholesterol itself was lacking [6].

It has been estimated that a $10 \%$ reduction in saturated fat intake within the UK population would be associated with a reduction in IHD mortality of between $20 \%$ and $30 \%$ [7]. According to WHO, [8] Up to 2.7 million lives could be saved annually with sufficient fruit and vegetable consumption. Low fruit and vegetable intake is among the top 10 selected risk factors for global mortality worldwide and causes about $19 \%$ of gastrointestinal cancer, about $31 \%$ of ischaemic heart disease and $11 \%$ of stroke $[8,9]$. Apart from being rich sources of carbohydrate, dietary fibre, antioxidants and other bioactive factors, fruit and vegetables are also rich sources of potassium, which is associated with lower blood pressure and a lower risk of stroke [7].

According to the Pakistan Demographic Survey (PDS) of the Federal Bureau of Statistics, in 2003 total percentage of death from non-communicable disease in Pakistan was $54.9 \%$ and out of this $13.8 \%$ was due to Cardiovascular Disease. Life expectancy at birth in Pakistan was 63.9 years for males and 63.8 years for females during 2006 as compared to 32.9 years and 34.4 years respectively during the year 1947 [10].

Dietary advice regarding cardiovascular disease (CVD) prevention is complex. Much confusion stems from the lack of definitive data on available diets and their potential health benefits. For years, the American Heart Association (AHA) has recommended a low-fat diet of $55 \%$ of total calories from carbohydrates, $30 \%$ from fat, and $15 \%$ from

*Corresponding author: Dr. Hamid Mahmood, Additional Medical Superintendent Punjab Institute of Cardiology, Lahore, Pakistan, Tel: 03334195250; E-mail: drhamidmahmood@hotmail.com

Received: February 03, 2015; Accepted: May 13, 2015; Published: May 17, 2015

Citation: Mahmood H, Abid AR, Riaz R, Mallick NH (2015) Relation of Cholestero Level to Dietary Fat Intake in Patients of Ischemic Heart Disease. Cardiol Pharmacol 4: 141. doi:10.4172/2329-6607.1000141

Copyright: (C) 2015 Mahmood H et al. This is an open-access article distributed under the terms of the Creative Commons Attribution License, which permits unrestricted use, distribution, and reproduction in any medium, provided the original author and source are credited. 
protein, with cholesterol restricted to $<300 \mathrm{mg}$ /day [11]. However, an unintended consequence of emphasizing this low-fat diet may have been to promote unrestricted carbohydrate intake [12].

In Pakistan ischemic heart disease has been studied previously but little data is available about cholesterol level and dietary habits in patients of ischemic heart disease [13,14]. This study is designed to evaluate the association of cholesterol level and dietary habits in patients of ischemic heart disease admitted with new onset acute coronary syndromes.

\section{Materials and Methods}

This comparative study was conducted at the emergency ward, coronary care units and cardiology wards of the Punjab Institute of Cardiology, Lahore from December 2007 till June 2008.

\section{Study patient groups}

Total 404 consecutive patients presenting with acute coronary syndromes admitted to the Punjab Institute of cardiology Lahore were studied as regard to their cholesterol levels and dietary habits.

Patients were divided into four groups.

Group I: Patients with normal cholesterol levels eating low fat diet. diet.

Group II: Patients with normal cholesterol levels eating high fat

Group III: Patients with high cholesterol levels eating low fat diet.

Group IV: Patients with high cholesterol levels eating high fat diet.

Association were studied with regard to normal and abnormal cholesterol levels.

\section{Inclusion criteria}

Patients presenting with new onset acute coronary syndromes were included in the study on the basis of presence of any two of the following criteria.

1) Chest pain consistent with myocardial ischemia.

2) Electrocardiographic changes: a) ST-Segment elevation $>2$ $\mathrm{mm}$ in at least two contiguous chest leads or $>1 \mathrm{~mm}$ in at least two contiguous limb leads. B) ST-segment depression of $>1 \mathrm{~mm}$ in two contiguous leads.

3) New or presumably New Left Bundle Branch Block on electrocardiogram.

4) Raised levels of cardiac enzymes CK-MB more than double.

\section{Exclusion criteria}

Patients were excluded on the basis of following criteria:

1) Patients not having new onset acute coronary event.

2) Patients already taking cholesterol lowering therapy i.e. a drug or on diet restriction.

\section{Data collection procedure}

A full history was taken particularly age, gender, occupation, address, history of smoking, diabetes mellitus, hypertension, ischemic heart disease and family history of ischemic heart disease. Time from onset of symptoms till arrival at the hospital was noted. Complete physical examination was done with emphasis on pulse, blood pressure, precordial examination and signs of congestive cardiac failure. ECG was done in all patients. Site of myocardial ischemia was noted for all the patients. Laboratory tests like CK-MB levels, Random blood sugar level and serum cholesterol level were done for all patients immediately after admission to the hospital. Baseline weight of all patients was done. Patients were given a detailed questionnaire to be filled in which included the dietary habits of the patients regarding intake of food rich in fat or low in fat content.

\section{Dietary analysis}

Patients' dietary questionnaires were analyzed for total daily caloric intake and their percentage of fat contents was calculated using the Food Composition Table for Pakistan [15].

\section{Reference levels}

Cholesterol: Normal level for cholesterol was $160 \mathrm{mg} / \mathrm{dl}$ from an overnight fasting blood sample [3].

Fat diet: After dietary analysis a level of fat diet $\leq 30 \%$ was considered as low fat diet and level of fat $>30 \%$ was taken as high fat diet.

\section{Statistical analysis}

All the data was analyzed by SPSS (Statistical Package for Social Sciences) Version 12.0 for Windows. Patient characteristics and dietary habits for different groups were compared using Chi-square test. Influence of various confounding factors on cholesterol levels were investigated using Pearson Chi-square. 5\% level of significance was used. All tests applied were two tailed.

\section{Results}

After fulfilling the inclusion criteria 404 patients were studied. Depending on the cholesterol level and fat intake the patients were divided into 4 groups. There were 176(45.5\%) patients in Group I, $76(18.2 \%)$ patients in Group II, $113(27.9 \%)$ patients in Group III and 39(9.6\%) patients in Group IV.

Mean age of the study population was $55.6 \pm 12.3$ years. Mean age was similar in all the groups $(\mathrm{p}<0.127)$. Overall $308(76.2 \%)$ patients were males and $96(23.8 \%)$ were females. Male to female ratio was similar in all the groups $(\mathrm{p}<0.275)$. Smoking was a risk factor in $150(37 \%)$ patients. Similar number of smokers was observed in all the groups $(\mathrm{p}<$ 0.938). Diabetes mellitus was present in 155(38.4\%) (Table 1). Diabetes mellitus was observed in 35(46.1\%) patients in Group II, $45(39.8 \%)$ in Group III, 62(35.2\%) in Group I and 13(33.3\%) in Group IV. There was a non-significant association of diabetes mellitus in the four groups $(p<0.369)$. Hypertension was observed in $187(46.3 \%)$ patients. Half of patients 57(50.4\%) were hypertensive in Group III, 81(46\%) in Group I, $34(44.7 \%)$ in Group II and $15(38.5 \%)$ in Group IV $(p<0.61)$. History of ischemic heart disease was observed in $147(36.4 \%)$. Similar number of patients had history of IHD in the 4 groups $(\mathrm{p}<0.841)$. Family history of IHD was observed in $139(34.4 \%)$ with a non-significant association between the groups $(\mathrm{p}<0.872)$ (Table 1$)$.

Mean heart rate at the time of presentation was $77.7 \pm 21.5 /$ minute. Heart rate was similar in Group I and III and II and IV ( $p<0.03)$. Mean systolic blood pressure was $123.3 \pm 30.8 \mathrm{~mm} \mathrm{Hg}$. It was similar in the 4 groups $(\mathrm{p}<0.865)$. Mean diastolic blood pressure was $76.4 \pm 16.9 \mathrm{~mm}$ $\mathrm{Hg}$. It was slightly higher in Group IV as compared to other groups however there was a non-significant association $(\mathrm{p}<0.918)($ Table 2$)$. Overall anterior wall MI occurred in 226(55.9\%) patients followed by inferior wall MI in 153(37.9\%), lateral wall MI in $12(3 \%)$, posterior 


\begin{tabular}{|c|c|c|c|c|c|c|}
\hline CHARACTERISTICS & $\begin{array}{c}\text { GROUP I } \\
n=176\end{array}$ & $\begin{array}{c}\text { GROUP II } \\
n=76\end{array}$ & $\begin{array}{c}\text { GROUP III } \\
n=113\end{array}$ & $\begin{array}{c}\text { GROUP IV } \\
\mathrm{N}=39\end{array}$ & $\begin{array}{l}\text { TOTAL } \\
n=404\end{array}$ & $P$ value \\
\hline AGE & $56.4 \pm 12.6$ & $57.9 \pm 12.7$ & $53.2 \pm 11.9$ & $53.7 \pm 13.2$ & $55.6 \pm 12.3$ & 0.127 \\
\hline $\begin{array}{l}\text { GENDER } \\
\text { MALE } \\
\text { FEMALE }\end{array}$ & $\begin{array}{c}142(80.7 \%) \\
34(19.3 \%)\end{array}$ & $\begin{array}{l}57(75 \%) \\
19(25 \%)\end{array}$ & $\begin{array}{l}82(72.6 \%) \\
31(27.4 \%)\end{array}$ & $\begin{array}{l}27(69.2 \%) \\
12(30.8 \%)\end{array}$ & $\begin{array}{c}308(76.2 \%) \\
96(23.8 \%)\end{array}$ & 0.275 \\
\hline SMOKING & $66(37.5 \%)$ & $28(36.8 \%)$ & $40(35.4 \%)$ & $16(41.6 \%)$ & $150(37 \%)$ & 0.938 \\
\hline DIABETES & $62(35.2 \%)$ & $35(46.1 \%)$ & $45(39.8 \%)$ & $13(33.3 \%)$ & $155(38.4 \%)$ & 0.369 \\
\hline HYPERTENSION & $81(46 \%)$ & $34(44.7 \%)$ & $57(50.4 \%)$ & $15(38.5 \%)$ & $187(46.3 \%)$ & 0.61 \\
\hline HO IHD & $64(36.4 \%)$ & $29(38.2 \%)$ & $38(33.6 \%)$ & $16(41 \%)$ & $147(36.4 \%)$ & 0.841 \\
\hline FAMILY HO IHD & $58(33 \%)$ & $29(38.2 \%)$ & $38(33.6 \%)$ & $14(35.9 \%)$ & $139(34.4 \%)$ & 0.872 \\
\hline HEIGHT mean feet & $5.4 \pm 0.76$ & $5.3 \pm 0.9$ & $5.6 \pm 0.8$ & $5.3 \pm 0.9$ & $5.4 \pm 0.8$ & 0.421 \\
\hline WEIGHT mean Kgs & $71.7 \pm 16.5$ & $69.2 \pm 19.9$ & $66.9 \pm 23.5$ & $67.9 \pm 16.4$ & $69.3 \pm 18.8$ & 0.282 \\
\hline BMI & 26.3 & 26.5 & 22.8 & 26.1 & 25.3 & \\
\hline WAIST & $29.6 \pm 13.4$ & $30.6 \pm 12.8$ & $27.3 \pm 15.1$ & $32.2 \pm 10$ & $29.4 \pm 13.6$ & 0.188 \\
\hline
\end{tabular}

$\mathrm{HO} \mathrm{IHD}=$ History of Ischemic heart disease

Table 1: Demographic characteristics of the study population.

\begin{tabular}{|c|c|c|c|c|c|c|}
\hline CHARACTERISTICS & $\begin{array}{c}\text { GROUP I } \\
n=176\end{array}$ & $\begin{array}{c}\text { GROUP II } \\
n=76\end{array}$ & $\begin{array}{c}\text { GROUP III } \\
n=113\end{array}$ & $\underset{n=39}{\text { GROUP IV }}$ & $\begin{array}{l}\text { TOTAL } \\
n=404\end{array}$ & $P$ value \\
\hline Pulse & $76 \pm 22.9$ & $80.7 \pm 17.9$ & $77.3 \pm 23.1$ & $80.5 \pm 15.2$ & $77.7 \pm 21.5$ & 0.03 \\
\hline Systolic BP & $122.6 \pm 29.2$ & $119.8 \pm 31.2$ & $123.6 \pm 36.4$ & $128.5 \pm 26.3$ & $123.3 \pm 30.8$ & 0.865 \\
\hline Diastolic BP & $75.8 \pm 16.8$ & $74.2 \pm 18.9$ & $77.5 \pm 16.9$ & $80 \pm 12.3$ & $76.4 \pm 16.9$ & 0.918 \\
\hline $\begin{array}{l}\text { Site of MI } \\
\text { Anterior wall } \\
\text { Inferior wall } \\
\text { Lateral wall } \\
\text { Posterior wall } \\
\text { LBBB }\end{array}$ & $\begin{array}{c}91(51.7 \%) \\
73(41.5 \%) \\
9(5.1 \%) \\
2(1.1 \%) \\
1(0.6 \%)\end{array}$ & $\begin{array}{c}44(57.9 \%) \\
25(32.9 \%) \\
2(2.6 \%) \\
0 \\
5(6.6 \%)\end{array}$ & $\begin{array}{c}70(61.9 \%) \\
38(33.6 \%) \\
1(0.9 \%) \\
1(0.9 \%) \\
3(2.7 \%\end{array}$ & $\begin{array}{c}21(53.8 \%) \\
17(43.6 \%) \\
0 \\
0 \\
1(2.6 \%)\end{array}$ & $\begin{array}{c}226(55.9 \%) \\
153(37.9 \%) \\
12(3.0 \%) \\
3(0.7 \%) \\
10(2.5 \%)\end{array}$ & 0.118 \\
\hline
\end{tabular}

$\mathrm{BP}=\mathrm{Blood}$ pressure; $\mathrm{LBBB}=\mathrm{Left}$ bundle branch block

Table 2: Presentation characteristics of the study population.

wall MI in 3(0.7\%) and new onset left bundle branch block in $10(2.5 \%)$ patients. Site of myocardial infarction was similar in the 4 groups with a non-significant association $(\mathrm{p}<0.118)$.

Mean BMI of Group I was 26.3, Group II 26.5, Group III 22.8 and Group IV was 26.1. Mean waist circumference was $29.4 \pm 13.6 \mathrm{cms}$. It was similar in the 4 four groups ( $\mathrm{p}<0.188$ ).

Mean caloric intake of the study patients was $2570.5 \pm 936.7$. Caloric intake was highest in Group I followed by Group III. Group II and IV had lower caloric intake than Groups I and III $(\mathrm{p}<0.0001)$. Fat intake was lower in Groups I and III than Groups II and IV ( $p<0.0001)$. Similarly percent fat was also lower in Group I and III as compared to Groups II and IV ( $\mathrm{p}<0.008)$ (Table 3).

Mean cholesterol level of the study population was $154.5 \pm 42.6$ $\mathrm{mg} / \mathrm{dl}$. Mean cholesterol level was highest in Group III $195.9 \pm 38.8$ $\mathrm{mg} / \mathrm{dl}$ followed by Group IV 193.6 $\pm 39.5,130.3 \pm 19.6$ in Group I and $129.1 \pm 20.4$ in Group II $(\mathrm{p}<0.0001)$. Mean LDL was $75.2 \pm 39.9 \mathrm{mg} /$ dl. Mean LDL level was higher in Group III and IV as compared to Groups I and II $(\mathrm{p}<0.0001)$. Mean HDL level $34.3 \pm 16.8 \mathrm{mg} / \mathrm{dl}$. Mean HDL was highest in Group IV $41.1 \pm 33.2$ and lowest in Group II 32.1 \pm 12.1 ( $\mathrm{p}<0.008$ ). Although Group I having largest number of patients had normal cholesterol level but still they had acute myocardial due to low mean HDL level of $33.2 \pm 11.2$. Group II patients although taking high fat diet had normal cholesterol with low HDL similar to Group I. Intake of fat had no influence on cholesterol and HDL levels. Mean triglyceride level was $167 \pm 124$. Mean triglycerides were highest in Group III $211 \pm 172.8$ followed by Groups IV, I and II ( $p<0.023)$ (Table 4).

\section{Discussion}

During the past 30 years, developing countries have undergone major changes that have been paralleled by a dramatic increase in mortality and morbidity from coronary heart disease. Changes in lifestyle that have been associated with economic growth and urbanization, coupled with reductions in morbidity and mortality from communicable disease and childbirth, have resulted in the sobering statistic that $80 \%$ of the global burden from cardiovascular disease now occurs in developing countries [16]. Indeed, it is estimated that unless current trends are halted, more than 1 billion people will die from cardiovascular disease in the first half of the 21 st century-the majority coming from developing countries, with most of the life-years lost occurring in middle age [16].

Radical dietary shifts in many developed and developing nations are supplanting traditional patterns of eating with a Western diet high in animal products and refined carbohydrates and low in whole grains, fruits, and vegetables. In China, for example, consumption of animal products increased by nearly 40\% between 1989 and 1997 [17] and fast food sales more than doubled between 1999 and 2005 [18]. Furthermore, consumption of soft drinks has soared in the United States and worldwide.

Iqbal et al. [19] assessed dietary patterns and risk of myocardial infarction (MI) in the INTERHEART study, a standardized casecontrol study involving participants from 52 countries. The authors identified 3 major dietary patterns that are largely consistent across different populations: Oriental (high intake of tofu and soy and other sauces), Western (high in fried foods, salty snacks, eggs, and meat), 


\begin{tabular}{|c|c|c|c|c|c|}
\hline Characteristics & $\begin{array}{c}\text { GROUP I } \\
\mathbf{n = 1 7 6}\end{array}$ & $\begin{array}{c}\text { GROUP II } \\
\mathbf{n = 7 6}\end{array}$ & $\begin{array}{c}\text { GROUP III } \\
\mathbf{n = 1 1 3}\end{array}$ & $\begin{array}{c}\text { GROUP IV } \\
\mathbf{n = 3 9}\end{array}$ & $\begin{array}{c}\text { TOTAL value } \\
\mathbf{n = 4 0 4}\end{array}$ \\
\hline Calories & $3018.9 \pm 1010.4$ & $2179 \pm 886.7$ & $2900 \pm 1000$ & $2186.3 \pm 851.3$ & $2570.5 \pm 936.7$ \\
\hline Fat Intake & $455.6 \pm 197.6$ & $722.4 \pm 321$ & $419.4 \pm 180.6$ & $739 \pm 441.8$ & $583.5 \pm 284.7$ \\
\hline Percent Fat & $15.9 \pm 5.9$ & $34.8 \pm 14.1$ & $15.6 \pm 6.7$ & $41.1 \pm 33.2$ & $26.8 \pm 14.9$ \\
\hline
\end{tabular}

Table 3: Dietary habits and fat intake of study patients.

\begin{tabular}{|c|c|c|c|c|c|}
\hline Characteristics & $\begin{array}{c}\text { GROUP I } \\
\mathbf{n = 1 7 6}\end{array}$ & $\begin{array}{c}\text { GROUP II } \\
\mathbf{n = 7 6}\end{array}$ & $\begin{array}{c}\text { GROUP III } \\
\mathbf{N = 1 1 3}\end{array}$ & $\begin{array}{c}\text { GROUP IV } \\
\mathbf{n = 3 9}\end{array}$ & $\begin{array}{c}\text { TOTAL } \\
\mathbf{n = 4 0 4}\end{array}$ \\
\hline Cholesterol & $130.3 \pm 19.6$ & $129.1 \pm 20.4$ & $195.9 \pm 38.8$ & $193.6 \pm 39.5$ & $154.5 \pm 42.6$ \\
\hline Ldl & $63.2 \pm 25.2$ & $65.1 \pm 23.5$ & $86.4 \pm 57.2$ & $86.3 \pm 53.8$ & $75.2 \pm 39.9$ \\
\hline Hdl & $33.2 \pm 11.2$ & $32.1 \pm 12.1$ & $35.1 \pm 17.8$ & $41.1 \pm 33.2$ & $34.3 \pm 16.8$ \\
\hline Triglycerides & $140 \pm 105.3$ & $124.9 \pm 69.4$ & $211.3 \pm 172.8$ & $195.7 \pm 150.3$ & $<0.0001$ \\
\hline
\end{tabular}

Table 4: Lipid profile of the study population.

and prudent (high in fruit and vegetables). Consistent with previous studies in single within-population cohort studies [20], the authors found an inverse association between the prudent pattern score and risk of MI and a significant positive association between the Western pattern score and increased risk of MI. The Oriental pattern was not significantly associated with risk. To go 1 step further, the investigators constructed a dietary risk score based on 7 food items on the foodfrequency questionnaire (meat, salty snacks, fried foods, fruits, green leafy vegetables, cooked vegetables, and other raw vegetables) and found that a higher score (indicating a poor diet) was strongly associated with MI risk: Those in the highest quartile of the score had nearly 2-fold increased risk, even after adjustment for established coronary risk factors. In sensitivity analyses, the investigators found a consistent association for the composite diet score between men and women and across different regions of the world (North America, Western Europe, Australia, central Europe, Middle East, Africa, south Asia, Southeast Asia, China, and South America). On the basis of an arbitrary cut point of the score (top 3 quartiles versus the bottom quartile), the investigators estimated that $30 \%$ of MI could be explained by unhealthy diets worldwide. These finding are consistent with our study as we observed higher intake of fats (unhealthy diets) in a minority of patients $25 \%$ as compared to a majority of patients having raised cholesterol level in the study.

Although Western-style changes in food patterns are widely believed to adversely influence risk of chronic diseases, few epidemiological studies have directly linked dietary patterns and mortality from coronary heart disease. The study by Iqbal et al. [19] is the first large study to quantify eating patterns in all geographic regions of the world. It provides evidence that despite different food habits in various populations, reproducible patterns can be found in diverse regions of the world. These findings are important because there has been a concern that dietary patterns derived through a datadriven approach such as principle-component analysis may be highly unstable and non-reproducible because of very different eating habits in different populations.

In recent years, dietary-patterning analysis has been increasingly used as an alternative method to traditional single nutrient analysis because it can assess cumulative effects of the overall diet [20]. Habitual intake patterns are typically quantified by statistical methods such as factor or cluster analysis or diet-quality indexes based on prevailing dietary recommendations or healthful traditional diets (eg. the Mediterranean diet). Principle-component analysis is commonly used to define dietary patterns using food consumption information to identify common underlying dimensions (factors or patterns) of food intake. The method aggregates specific food items based on the degree to which these food items are correlated with each another. A summary score for each pattern is then derived and can be used to examine relationships between various eating patterns and outcomes of interest such as coronary heart disease and other chronic diseases. Previous validation studies found that 2 major patterns (the prudent and Western patterns) identified through principle-component analysis of food consumption data assessed by food frequency questionnaires were reproducible over time and correlated reasonably well with the patterns identified from diet records [20].

In a similar, population-based control study, Kabagambe et al. [21] have estimated the population attributable risk (PAR) for major myocardial infarction among 889 Hispanic Americans living in the central valley of Costa Rica who had no history of diabetes, hypertension, or prior medical therapy. In multivariate analyses, abdominal obesity $(\mathrm{PAR}=29.3 \%)$ and smoking $(\mathrm{PAR}=25.6 \%)$ were the 2 leading risk factors for myocardial infarction. In their study, important gender differences were noted, with men more likely to smoke than women ( $54 \%$ versus $12 \%$ ) and women more likely to have abdominal obesity (35\% versus $9 \%$ ). With regard to diet, the majority did not meet American Heart Association or World Health Organization/Food and Agriculture Organization dietary guidelines. Using a healthy dietary score, energy-adjusted intakes of saturated fat $(96 \%$ had intakes > $7 \%$ energy) and trans fat ( $63 \%$ had intakes $>1 \%$ energy) were high, whereas energy intake from polyunsaturated fat $(25 \%$ had $<5 \%$ energy intake) and fiber intake ( $53 \%$ with $\leq 25 \mathrm{~g} / \mathrm{d}$ ) were low. Kabagambe et al. [21] have observed that the consumption of a healthy diet and increased physical activity were inversely related to occurrence of myocardial infarction. Further, the diet of current smokers was poorer than that of those who never smoked. These 2 observations have led the investigators to recommend that joint messaging be used for diet and smoking; that is, smoking cessation and improved dietary instructions should be combined-especially among male smokers, whose diets were usually low in fruits, vegetables, and other nutrients. In our study we observed a non-significant association of risk factors in the four groups. In our study overall $308(76.2 \%)$ patients were males and $96(23.8 \%)$ were females. Male to female ratio was similar in all the groups $(p<0.275)$. Similar numbers of smokers were observed in all the groups $\mathrm{p}<0.938$. Diabetes mellitus was observed in 35(46.1\%) patients in Group II, 45(39.8\%) in Group III, 62(35.2\%) in Group I and $13(33.3 \%)$ in Group IV ( $<<0.369)$. Hypertension was observed in 187(46.3\%) patients. History of ischemic heart disease was observed in $147(36.4 \%)$. Similar number of patients had history of IHD in the 4 groups ( $\mathrm{p}<0.841)$. Family history of IHD was observed in $139(34.4 \%)$ with a non-significant association between the groups $(\mathrm{p}<0.872)$. 
Lanas et al. [22] carried out a case-control study involving 1237 cases of first acute myocardial infarction from the 6 Latin American countries of Argentina, Brazil, Colombia, Chile, Guatemala, and Mexico, which were part of the larger INTERHEART study involving 15,152 cases of first acute myocardial infarction in 52 countries worldwide. Their work identifies risk factors for acute myocardial infarction in Latin America and provides important information about the population-attributable risk (PAR) in this region. Although the 9 risk factors for coronary heart disease: abnormal lipid levels, smoking, hypertension, diabetes, abdominal obesity, psychosocial stress, regular physical activity, and consumption of fruits, vegetables, and alcohol accounted for $90 \%$ or more of the PAR for both men and women worldwide, an important difference was noted in Latin America. The PAR for abdominal obesity, defined by increased waist-to-hip ratio, was more important in the Latin American countries than in the rest of the world. The PAR for abdominal obesity in the Latin American countries studied was $48.5 \%$, followed by $40.8 \%$ for dyslipidemia and $38.4 \%$ for smoking, these risk factors accounted for $77.6 \%$ of the PAR in Latin America. Interestingly, the PAR for waist-to-hip ratio in Chile was only $16.6 \%$, whereas values $>50 \%$ for the PAR of waist-to-hip ratio were noted in the other Latin American countries. In the study, 89.3\% of cases and $95.0 \%$ of controls were Latino/Aboriginal-a group that, when compared with those of European origin $(9.1 \%$ of cases and $3.9 \%$ of controls), would be expected to have a higher prevalence of abdominal obesity. Although no specific information is given for the ethnicity of patients from Chile, it is possible that the observation of lower waist-to-hip ratio was confounded by a higher number of cases with European origin in the Chilean group of the study. In our study Patients were divided into four groups. Group I 176(45.5\%) Patients with normal cholesterol levels eating low fat diet. Group II 76(18.2\%) Patients with normal cholesterol levels eating high fat diet. Group III 113(27.9\%) Patients with high cholesterol levels eating low fat diet. Group IV 39(9.6\%) Patients with high cholesterol levels eating low fat diet. Association were studied with regard to normal and abnormal cholesterol levels. There was a non-significant association of risk factors among the four groups.

It is clear that a worldwide emphasis must be placed on changing lifestyles, and this emphasis should include nutrition, physical activity, and avoidance of tobacco products. Current global information indicates that more than 1.3 billion adults are overweight or obese [23]. Using the revised World Health Organization definition of obesity that adjusts for ethnic differences, 1.7 billion children are classified as obese [24].

The appeal of the Western dietary pattern to children and adolescents is of particular concern. Because children are more susceptible to the influence of food advertising and promotion, globalization of fast foods and soft drinks may affect their eating behaviors even more than adults' habits [25]. Children tend to adapt to global culture quickly and therefore bear watching for behaviors that will shape their food and beverage choices and affect their body weight, activity levels, and long-term risk for adverse health consequences [26]. Furthermore, as many developing countries experience the dual burdens of undernutrition and overnutrition, low-quality diets not only will increase the risk of chronic diseases but also may exacerbate the problem of undernutrition in the form of micronutrient deficiency, especially in children [27].

\section{Conclusion}

Dietary intake of fat has no influence on cholesterol levels. Low $\mathrm{HDL}$ is an important risk factor leading to acute myocardial infarction and is not influenced by fat intake in diet.

\section{References}

1. Tu JV, Naylor CD, Austin $P$ (1999) Temporal changes in the outcomes of acute myocardial infarction in Ontario, 1992-1996. CMAJ 161: 1257-1261.

2. Pashos CL, Newhouse JP, McNeil BJ (1993) Temporal changes in the care and outcomes of elderly patients with acute myocardial infarction, 1987 through 1990. JAMA 270: 1832-1836.

3. Grundy SM, Cleeman JI, Merz CNB, Brewer HB, Clark LT, Hunninghake DB (2004) Implications of Recent Clinical Trials for the National Cholestero Education Program Adult Treatment Panel III Guidelines. J Am Coll Cardio 44:720-32.

4. Law MR, Wald NJ, Thompson SG (1994) By how much and how quickly does reduction in serum cholesterol concentration lower risk of ischaemic heart disease? BMJ 308: 367-372

5. Law MR, Wald NJ, Rudnicka AR (2003) Quantifying effect of statins on low density lipoprotein cholesterol, ischaemic heart disease, and stroke: systematic review and meta-analysis. BMJ 326: 1423.

6. Waters DD, Guyton JR, Herrington DM, McGowan MP, Wenger NK, Shear C (2004) Treating to New Targets (TNT) Study: Does lowering low-density lipoprotein cholesterol levels below currently recommended guidelines yield incremental clinical benefit? Am J Cardiol 93:154-158.

7. Marmot M (1994) The cholesterol papers. BMJ 308: 351-352.

8. World Health Report- Reducing Risks, Promoting Healthy Lives (2002) WHO

9. Diet, Nutrition and the Prevention of Chronic Diseases (2003) WHO

10. Nishtar S (2007) Health Indicators of Pakistan: Gateway Paper II, Heart File Pakisthan.

11. Krauss RM, Eckel RH, Howard B (2000) American Heart Association dietary guidelines, revision 2000: a statement for healthcare professionals from the Nutrition Committee of the American Heart Association. Circulation 102:2296 -311 .

12. Weinberg SL (2004) The diet-heart hypothesis: a critique. J Am Coll Cardiol 43: 731-733

13. Samad Z, Rashid A, Khan MA, Mithani S, Khan MH, et al. (2002) Acute myocardial infarction: profile and management at a tertiary care hospital in Karachi. J Pak Med Assoc 52: 45-50.

14. Siddiuqi AH, Kayani AM (2000) Acute myocardial infarction - clinical profile of 1000 cases. Pakistan Heart J 32, 33:42-45.

15. T Hussain (2008) Food Composition Table for Pakistan. Planning and Development Division, Ministry of Planning and Development, Department of Agricultural Chemistry and Human Nutrition, NWFP, Agricultural University, Peshawar.

16. Lopez A, Mathers C, Ezzati M, Jamison D, Murray C (2006) Global Burden of Disease and Risk Factors. New York.

17. Popkin BM, Du S (2003) Dynamics of the nutrition transition toward the animal foods sector in China and its implications: a worried perspective. J Nutr 133: 3898S-3906S.

18. Frazão E, Meade B, Regmi A (2008) Converging patterns in global food consumption and food delivery systems. Amber Waves 6:22-29.

19. Iqbal R, Anand S, Ounpuu S, Islam S, Zhang X, et al. (2008) Dietary patterns and the risk of acute myocardial infarction in 52 countries: results of the INTERHEART study. Circulation 118: 1929-1937.

20. Hu FB, Willett WC (2002) Optimal diets for prevention of coronary heart disease. JAMA 288: 2569-2578.

21. Kabagambe EK, Baylin A, Campos H (2007) Nonfatal acute myocardial infarction in Costa Rica: modifiable risk factors, population-attributable risks and adherence to dietary guidelines. Circulation 115: 1075-1081.

22. Lanas F, Avezum A, Bautista LE, Diaz R, Luna M, et al. (2007) Risk factors for acute myocardial infarction in Latin America: the INTERHEART Latin American study. Circulation 115: 1067-1074.

23. Popkin BM (2007) Understanding global nutrition dynamics as a step towards controlling cancer incidence. Nat Rev Cancer 7: 61-67. 
Citation: Mahmood H, Abid AR, Riaz R, Mallick NH (2015) Relation of Cholesterol Level to Dietary Fat Intake in Patients of Ischemic Heart Disease. Cardiol Pharmacol 4: 141. doi:10.4172/2329-6607.1000141

Page 6 of 6

24. Hossain P, Kawar B, El Nahas M (2007) Obesity and diabetes in the developing world--a growing challenge. N Engl J Med 356: 213-215.

25. Adair LS, Popkin BM (2005) Are child eating patterns being transformed globally? Obes Res 13: 1281-1299.
26. Ludwig DS (2007) Childhood obesity--the shape of things to come. N Engl J Med 357: 2325-2327.

27. Hawkes C (2006) Uneven dietary development: linking the policies and processes of globalization with the nutrition transition, obesity and diet-related chronic diseases. Global Health 2: 4 